PiJIES: Pedagogik Journal of Islamic Elementary School April 2018, Vol.1, No.1, hal. 73-80

ISSN(P): 2356-1483; ISSN(E): 2615-3904

(c) 2018 PGMI IAIN Palopo. http:// ejournal-iainpalopo.ac.id/ PiJIES

\title{
PENINGKATAN KETERAMPILAN MEMBACA MELALUI STRATEGI KNOW WANT TO LEARN (KWL)
}

\author{
Karmilasari \\ Institut Agama Islam Negeri Palopo \\ Jl. Agatis Balandai Kota Palopo, 91914 \\ E-mail: mhilakarmilasari@gmail.com
}

\begin{abstract}
The aim of this research is to apply Know Want to Learn strategy to improve reading skill in second grade students of SDN 245 Temboe. This research is a type of Classroom Action Research (PTK) conducted in collaboration with teachers through the use of Hopkins model consisting of 4 stages of planning, implementation, observation, and reflection. The subjects of the study were the students of class II SDN 245 Temboe which amounted to 19 students. The data collection technique used is by observation, test and documentation. The research data obtained is analyzed by using statistical formula (percentage) to express descriptively the research result. Furthermore, to discuss and explain the results of research that is quantitative descriptive then used data analysis techniques by reduction, presentation and drawing conclusions. With the implementation of Know Want to Learn (KWL) strategy can improve reading skill in second grade students of SDN 245 Temboe, the improvement is proved by the increasing of average score of students reaching Minimum Exhaustiveness Criteria (KKM) and number of students on pre-action test reaching KKM amounted to $26.31 \%$ with an average score of 59, in the first cycle the number of students who reached the KKM of $47.36 \%$ with an average score of 66, and in the second cycle the number of students who reached the KKM of 94.73\% 85. Thus, the reading skill in class II SDN 245 Temboe by applying the Know Want to Learn strategy (KWL) conducted from the first cycle to the second cycle shows significant results.
\end{abstract}

Keywords: Reading Skill, Know Want to Learn (KWL)

\begin{abstract}
Abstrak
Penelitian ini bertujuan dengan menerapkan strategi Know Want to Learn dapat meningkatkan keterampilan membaca pada siswa kelas II SDN 245 Temboe. Penelitian ini merupakan jenis Penelitian Tindakan Kelas (PTK) yang dilakukan secara kolaborasi bersama guru melalui penggunaan model Hopkins yang terdiri dari 4 tahap yaitu perencanaan, pelaksanaan, observasi, dan refleksi. Subjek penelitian adalah siswa-siswi kelas II SDN 245 Temboe yang berjumlah 19 siswa. Adapun teknik pengumpulan data yang digunakan yaitu dengan observasi, tes dan dokumentasi. Data penelitian yang diperoleh dianalisi dengan menggunakan rumus statistik (persentasi) untuk mengungkapkan secara deskriptif hasil penelitian. Selanjutnya, untuk membahas dan menjelaskan hasil penelitian yang bersifat kuantitatif deskriptif maka digunakan teknik analisis data secara reduksi, penyajian dan penarikan kesimpulan. Dengan penerapan strategi Know Want to Learn (KWL) dapat meningkatkan keterampilan membaca pada siswa kelas II SDN 245 Temboe, peningkatan tersebut dibuktikan dengan adanya peningkatan jumlah nilai rata-rata siswa yang mencapai Kriteria Ketuntasan Minimal (KKM) dan jumlah siswa pada tes pratindakan yang mencapai KKM sebesar 26,31\% dengan nilai rata-rata 59, pada siklus I jumlah siswa yang mencapai KKM sebesar 47,36\% dengan nilai rata-rata 66, dan pada siklus II jumlah siswa yang mencapai KKM sebesar $94,73 \%$ dengan nilai rata-rata 85 . Dengan demikian, keterampilan membaca di kelas II
\end{abstract}




\section{4 | Karmilasari}

SDN 245 Temboe dengan menerapkan strategi Know Want to Learn (KWL) yang dilakukan mulai dari siklus pertama sampai dengan siklus kedua menunjukkan hasil yang signifikan.

Kata Kunci,: Keterampilan Membaca, Know Want to Learn (KWL).

\section{PENDAHULUAN}

Bahasa sebagai peran sentral dalam keberhasilan peserta didik selain itu bahasa juga penting dalam kehidupan manusia karena merupakan salah satu alat komunikasi manusia sehari-hari. Hal ini sejalan dengan pendapat Sukirman dan Edhy (2010:3) menyatakan bahasa adalah bahasa merupakan suatu oral atau simbol lisan yang arbitrer dan konvensional digunakan pada sekelompok masyarakat untuk berkomunikasih dan berinteraksi antara sesamanya berdasarkan budaya masing-masing. Sedangkan Dalman berpendapat (2014:5) Membaca adalah suatu proses atau kegiatan kognitif yang berupaya untuk mencari berbagai informasi yang terdapat di dalam sebuah tulisan. Pada dasarnya belajar bahasa adalah belajar berkomunikasi. Menurut Nida dalam Tarigan (1981:1) belajar bahasa menekankan empat komponen keterampilan, yaitu:keterampilan menyimak, keterampilan berbicara, keterampilan membaca dan keterampilan menulis. Pada setiap keterampilan, berhubungan dengan setiap keterampilan yang lain. Keterampilan dapat dikuasai secara praktik dan banyak pelatihan keterampilan. Hal ini sejalan dengan pendapat Tarigan (1980:1) dan Dawson (1963: 27) menyatakan melatih keterampilan dalam berbahasa sama dengan melatih keterampilan berpikir seseorang. Sebagai keterampilan dari berbahasa, keterampilan membaca memunyai kedudukan yang sangat strategis karena memlalui membaca orang dapat memahami kata yang diutarakan seseorang. Seperti pendapat Wahyuningsih (2012: xi) menyatakan membaca begitu penting bagi masyarakat sekarang ini. Membaca adalah sumber mendapatkan informasi dari teks tertulis. Keterampilan membaca merupakan kemampuan siswa yang diperoleh selama mengikuti suatu proses pembelajaran.

Berdasarkan observasi yang dilakukan, bahwa ada 19 siswa yang menjadi sampel sekaligus ikut dalam melakukan tes awal ternyata 2 siswa (10\%) dikategorikan "sangat baik", 3 siswa (15\%) dikategorikan "baik", 8 siswa (42\%) dikategorikan "cukup", 4 siswa (21\%) dikategorikan "kurang" dan 2 siswa (10\%) dikategorikan " gagal". Salah satu yang menyebabkan kurangnya membaca pada siswa bukan hanya terdapat pada kemalasan membaca pada siswa tetapi juga dari lingkungan. Hal ini sejalan dengan pendapat Meliyawati (2016: 3) berpendapat membaca merupakan suatu aktivitas komplek yang melibatkan berbagai faktor yaitu dari dalam maupun di luar diri pembaca. Pendapat lain oleh Femi Olivia (2008: 18) menyatakan jika anak anda ingin belajar menikmati membaca sebaiknya jangan memicu 
perasaan negatif terhadap membaca untuk meningkatkan keterampilan membaca anak. Juga, jangan memusatkan perhatian pada kesalahankesalahan atau masalah-masalah yang ditimbulkan oleh anak. Sedangkan Burhanuddin (2004: 49) berpendapat bahwa bila bahan yang dibaca itu sesuai dengan minat dan hobby/ kesenangan, dapat menghibur para pembaca dan membantu dalam menghadapi berbagai persoalan. Selain dari lingkungan pembaca, adapun faktor yang juga memengaruhi yaitu penggunaan strategi yang digunakan oleh guru selama proses pembelajaran. Menurut Syaiful dan Aswan (2010:5) strategi merupakan suatu tindakan dalam usaha untuk mencapai suatu sasaran yang ditentukan.pendapat lain oleh Warni Tune (2016: 16) pada strategi pembelajaran kegiatan berinteraksi siswa dengan guru serta lingkungan sebagai sumber pembelajaran yang menyenangkan serta menggairakan bagi siswa.

Permasalah tersebut harus segera diatasi agar kualitas pembelajaran keterampilan membaca siswa dapat meningkat. Adapun strategi yang dapat digunakan guru yaitu strategi Know Want to Learn (KWL). Menurut Ni Putu Candra Dewi (2014:4) Strategi KWL merupakan strategi yang menuntut siswa untuk memahami isi bacaan, membuat pertanyaan dan membaca. Menurut Farida Rahim (2008: 41) Strategi KWL memiliki tiga langkah K (what I know) yaitu apa yang telah diketahui, langkah W (what to know) yaitu apa yang ingin di ketahui dan langkah $\mathrm{L}$ (what I learn) yaitu apa yang sudah dipelajari. Dari ketiga langkah pada KWL tersebut berguna untuk meningkatkan keterampilan membaca siswa seperti siswa mampu memberikan pendapat, menentukan ide, menyusun pertanyaan secara spesifik, dan mengecek hal-hal yang ingin diketahui/ dipelajari siswa dari suatu bacaan. pemilihan strategi pembelajaran harus tepat dengan pembelajaran, agar proses belajar mengajar dapat berjalan dengan baik. Seperti yang dipaparkan oleh Amaliyah (2012:55) berpendapat bahwa penggunaan metode atau strategi pembelajaran harus sesuai dengan pembelajaran yang diajarkan kepada siswa.

\section{METODE}

Jenis penelitian ini yaitu Penelitian Tindakan Kelas (PTK) yang berfokuskan pada aktivitas pembelajara didalam kelas. Menurut Muhadi (2011:45) PTK merupakan suatu metode penelitian yang dapat menarik perhatian orang-orang terutama yang bergerak pada bidang praktisi pendidikan maupun di ilmu pengetahuan sosial. PTK ini menggunakan model yang diterapakan oleh Hopkins yang membentuk spiral yang memulai dari merasakan adanya masalah sebelum menyusun perencanaan, setelah itu melakukan tindakan, observasi, dan mengadakan refleksi sebelum 


\section{6 | Karmilasari}

melaksanakan rencana ulang, menurut Hopkins (Wina Sanjaya, 2009:53-54). Lokasi penelitian di laksanakan di SDN 245 Temboe Kec. Larompong Selatan Kab. Luwu. Adapun subjek dari penelitian yaitu siswa-siswi kelas II SDN 245 Temboe yang berjumlah 19 yaitu 10 dari laki-laki dan 9 dari perempuan. Pengumpulan data mengunakan teknik dengan mengukur hasil belajar siswa, melakukan observasi dan dokumentasi.

Pengolaan data dilakukan setelah semua data terkumpul, selanjutnya akan dianalisis secara kuantitatif yaitu dengan mencari skor nilai rata-rata dan presentase siswa, dan secara kuanlitatif dilakukan terhadap data yang diperoleh melalui observasi aktivitas belajar siswa dan guru dalam penerapan strategi KWL untuk meningkatkan keterampilan membaca. Suharsimi (2002:264) untuk mengetahui pencapaian kriteria nilai rata-rata siswa yaitu dengan menganalisis semua nilai yang diperoleh siswa kemudian dibagi dengan semua jumlah siswa yang mengikuti tes penelitian tersebut. Anas Sudijono (2009: 43) rumus untuk mencari frekuensi bila target ketegori tuntas $80 \%-100 \%$ dan sebanyak $<40 \%$ berada dalam kategori tidak tuntas.

\section{HASIL PENELITIAN}

Keterampilan membaca siswa di kelas II SDN 245 Temboe Kec. Larompong Selatan Kab. Luwu dapat diketahui selalu mengalami peningkatan. Hal tersebut dapat diketahui bedasarkan hasil observasi yang dilakukan pada setiap pertemuan mulai dari prasiklus, siklus I kemudian siklus II. Gambar diagram peningkatan yaitu sebagai berikut;

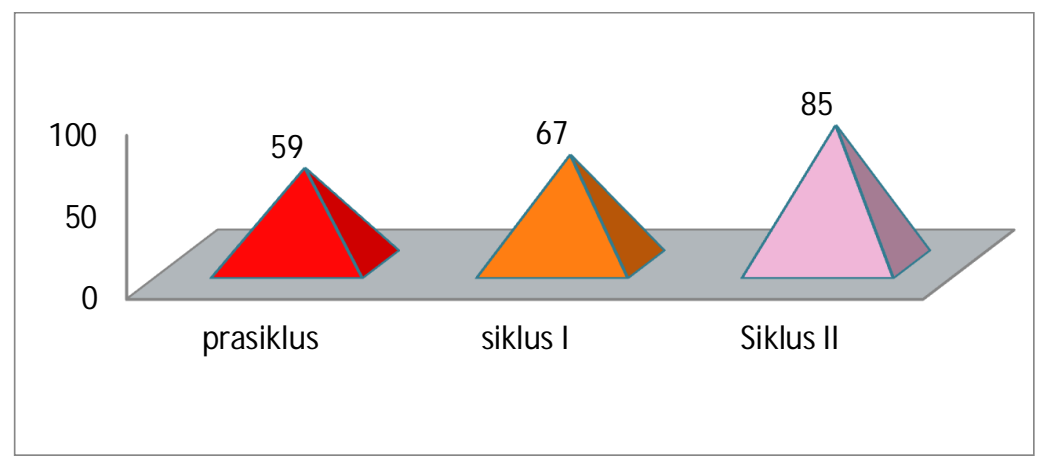

Diagram Tahap Prasiklus, Siklus I dan Siklus II

Diagram tersebut menunjukkan keterampilan membaca siswa kelas II SDN 245 Temboe Kec. Larompong Selatan Kab. Luwu pada tahap prasiklus nilai rata-rata siswa mencapai 59 dengan presentasi ketuntasan $26,31 \%$ dan belum cukup untuk memenuhi nilai KKM dan pada tahap siklus I dan berlanjut ke siklus II peneliti menggunakan strategi pembelajaran Know 
Want to Learn (KWL) dan meningkat dengan nilai rata-rata mencapai 70 dan 85 dengan presentasi ketuntasan 94,73\%. Jadi, penerapan strategi Know Want to Learn pada pembelajaran dapat meningkatkan keterampilan membaca siswa.

\section{PEMBAHASAN}

P Penerapan strategi Know Want to Learn (KWL) pada siswa kelas II SDN 245 Temboe Kec. Larompong Selatan Kab. Luwu dilakukan sebagai upaya untuk meningkatkan keterampilan membaca siswa. Pelaksanaan pembelajaran terdiri dari 4 langkah pembelajaran yaitu: 1) Tahap menyampaikan tujuan pembelajaran, 2) Tahap menjelaskan langkah-langkah strategi KWL, 3) Tahap melaksanakan strategi KWL, dan 4) Tahap membaca, memahami dan menyimpulkan teks bacaan. Keempat langkah tersebut dirangkum menjadi beberapa kegiatan yaitu; 1)Kegiatan awal, 2) Kegiatan inti, dan 3) Kegiatan akhir. Langkah-langkah pembelajaran yang dilakukan adalah memahami dan menyimpulkan teks bacaan. Aktivitas yang dilakukan siswa untuk memahami dan menyimpulkan teks bacaan yang berhubungan dengan materi pelajaran.Sebelum kegiatan ini dilakukan, terlebih dahulu guru mengecek pemahaman yang telah dimiliki siswa.Setelah itu, siswa melanjutkan aktivitasnya dengan mengerjakan tabel KWL (Know want to Learn).

Penerapkan strategi Know Want to Learn (KWL) merupakan salah satu upaya guru untuk meningkatkan keterampilan membaca siswa. Terpenting adalah pemberian motivasi kepada siswa untuk melaksanakan aktifitas belajar, karena dengan adanya motivasi dapat menjadi dorongan mental untuk siswa mau dan ingin melakukan aktifitas belajar dengan semangat dan lebih aktif sehingga timbul perasaan untuk menjadi lebih baik lagi, sehingga menciptakan situasi pembelajaran yang afektif. Hal ini sejalan dengan pendapat David McClelland (Hamzah B. Uno, 2015:) mengatakan bahwa: A motive is the redintegration by a cue of a change in an affective situation, berarti motif merupakan implikasi dari perubahan dan adanya perbedaan situasi yang diharapkan. Pemberian motivasi dapat dilakukan oleh guru dengan memberikan sugesti-sugesti positif ketika siswa merasa tertekan atau stres. Hal ini disebabkan ketika sedang stres, hormon norefinephrin akan terangsang sehingga menstimulasi pengambilan keputusan dan motivasi siswa dalam belajar (Rustan, 2017).

Selain pemberian motivasi guru juga memberikan hadiah terhadap siswa yang mendapatkan nilai tertinggi setelah melakukan tes pada akhir tes untuk membangkitkan semangat belajar. Seperti pendapat Mamiq Gaza (2012:88) teknik pemberian reward atau bonus belajar meneyenangkan bagi 


\section{8 | Karmilasari}

siswa yang berhasil menunjukkan perilaku-perilaku positif tertentu. Pendapat lain yang sama yaitu B.F Skinner (Sudarwan Danim dan Khairil, 2014:107) siswa akan mengulangi perilaku yang diinginkan jika perilaku yang positif. Penguatan positif atau "imbalan" dapat mencakup penguatan verbal seperti "bagus", "bagus sekali", "sukses selalu", "pertahankan prestasimu", dan sebagainya.

Hasil penelitian dengan menggunakan strategi Know Want to Learn (KWL) menunjukkan adanya peningkatan keterampilan membaca siswa pada pembelajaran Bahasa Indonesia. Peningkatan tersebut dapat diketahui berdasarkan persentase ketuntasan belajar siswa yaitu prasiklus 26,31\%, siklus I 47,36\%, dan siklus II mencapai 94,73\% jawaban-jawaban yang tuliskan siswa pada akhir siklus berdasarkan pengetahuan mereka setelah mengikuti pelajaran. Menurut Lindgren pada Agus Suprijono (2014:7) hasil dari suatu pembelajaran yaitu kecakapan dalam berbicara, menemukan informasi, menjelaskan pengertia dan adanya perubahan sikap.

Hasil penelitian ini tampak bahwa model atau strategi pembelajaran memiliki pengaruh dalam meningkatkan hasil belajar siswa, hal ini sejalan dengan Slameto (2015:54) berpendapat yaitu hasil belajar berpengaruh pada penggunaan model pembelajaran selain faktor dari dalam maupun diluar individu. Untuk memilih model atau strategi pembelajaran tidak boleh sembarangan ada beberapa faktor yang harus dilihat, seperti pendapat Winarno dalam Syaiful Bahri (1994:71) yaitu harus sesuai dengan tujuan, jenis dan fungsi pembelajaran. Serta fasilitas yang digunakan dapat menciptakan situasi belajar yang aktif. Hal ini sejalan dengan pendapat senada Firman yang meyatakan bahwa seorang siswa dikatakan telah memahami suatu konsep jika memiliki kemampuan untuk menangkap makna dari informasi yang diterima yang berupa: 1) menafsirkan bagan, diagram atau grafik, 2) menerjemahkan suatu pernyataan verbal ke dalam formula matematis, 3) memprediksikan berdasarkan kecenderungan tertentu (interpolasi dan ekspolasi), 4) mengungkapkan suatu konsep dengan katakata sendiri.

Hal ini menunjukkan bahwa penerapan strategi KWL adalah suatu strategi yang sangat baik diterapkan dalam pelajaran Bahasa Indonesia untuk meningkatkan keterampilan membaca siswa. ada bagian ini, alur penjelasannya hampir sama dengan pembahasan rumusan masalah pertama.

\section{PENUTUP}

Kesimpulan hasil dari penelitian dan pembahasan pada bab-bab sebelumnya.

\section{PALITA: Journal of Social-Religion Research}


Penggunaan strategi Know Want to Learn (KWL) pada pembelajaran membaca pada siswa di kelas II SDN 245 Temboe menggunakan berbagai cara seperti membuat kelompok kecil untuk mengadakan diskusi pada pelajaran Bahasa Indonesia dengan membaca cerita dan siswa mampu membaca, memahami serta dapat menyimak materi pembelajaran dan kemudian siswa mempraktekkannya secara langsung dengan mengerjakan tugas-tugas yang diberikan oleh guru. Selain menerapakan strategi KWL, guru juga memberikan sedikit permainan dalam belajar agar kelas tampak hidup dan penuh keceriaan serta siswa lebih aktif dalam menjawab pertanyaan guru.

Peningkatan keterampilan membaca siswa, berdasarkan hasil yang dicapai dari tahap pratindakan nilai terata siswa sebesar 59 mengalami peningkatan dari siklus I dan siklus II nilai terata siswa meningkat menjadi 85 dengan pencapaian KKM sebesar 94,73\% pada siklus II. Jadi, dapat disimpulkan bahwa penggunaan strategi Know Want to Learn (KWL) pada pelajaran Bahasa Indonesia dapat meningkatkan keterampilan membaca siswa di kelas II SDN 245 Temboe Kecamatan Larompong Selatan Kabupaten Luwu.

\section{DAFTAR PUSTAKA}

Anonim. Tingkat Pemahaman Konsep. http://www.eurekapendidikan.Com/ 2016 /12/tingkat-pemahaman-konsep.html diakses pada tanggal 26 agustus 2017

Amaliyah, dkk. 2012. Jurnal Pengaruh Strategi Know Want to Learn (KWL) dan minat Membaca Terhadap Kemampuan Membaca Intensif Siswa SMP Negeri di Temanggung. (diakses;e-mail: papiku_jc_me@yahoo.com).

Arikunto, Suharsimi. 2002. Dasar-dasar Evaluasi Pendidikan. (Ed.Revisi III; Jakarta: Bumi Aksara).

Bahri, Syaiful Djamarah \& Aswan Zain. 2010. Strategi Belajar Mengajar. (cet,4; Jakarta: Rineka Cipta).

Dalman.2014. Keterampilan Membaca.(Ed.1, cet. 2, Jakarta: PT Rajagrafindo Persada).

Danim, Sudarwan. 2011. Pengantar Pendidikan, Cet. II. Bandung: Alfabeta.

Dawson, Mildred A. [et.al]. 1963. Guiding Language Learning. New York: Harcourt Brace \& World, Inc.

Dewi, Ni Putu Candra, dkk. 2014. Jurnal Penerapan Strategi KWL (Know Want to Learn) Untuk Meningkatkan Kemampuan Membaca Intensif Siswa di Kelas VII SMP Negeri I Sawan. (diakses; e-mail @undiksha.ac.id). 


\section{0 | Karmilasari}

Gaza, Mamiq. 2012. Bijak Menghukum Siswa, Cet. I, Jokjakarta: Ar-ruzz Media. Harris, David P. 1969. Testing English as a Second Language. New Delhi: Tata mc. Graw-Hill.

Nida, Eugene A.1957. Learning a Foreign Language. Michigan, Ann Arbor: Cushing-Molly, Inc.

Meliyawati. 2016. Pemahaman Dasar Membaca. Yogyakarta: Deepublish.

Muhadi. 2011. Penelitian Tindakan Kelas. Yogyakarta: Shira Media

Nurdjan, Sukirman dan Edhy Rustan. 2010. Kunci Sukses Berbahasa Indonesia. (Palopo: Lembaga Penerbitan STAIN (LPS).

Olivia, Femi. 2008. Tool For Study Skills Teknik Membaca Efektif. Jakarta: PT Gramedia.

Rahayu, Wahyuningsih. 2012. Model Pembelajaran Komeks Bermuatan Nilainilai Pendidikan Karakter Aspek Membaca di SD. Yogyakarta: Deepublish

Rahim, Farida. 2008. Pengajaran Membaca di Sekolah Dasar. Jakarta: Bumi Aksara.

Rustan, E. (2017). Learning Creative Writing Model Based on Neurolinguistic Programming. International Journal of Language Education and Culture Review, 3(2), 13-29. https:/ / doi.org/ 10.21009/ IJLECR.032.02

Salam, Burhanuddin. 2004. Cara Belajar Yang Sukses Di Perguruan Tinggi. Jakarta: PT Rineka Cipta.

Sanjaya, Wina. 2009. Penelitian Tindakan Kelas. Jakarta: Kencana Prenadamedia Group.

Sudijono, Anas. 2009. Pengantar Evaluasi Pendidikan. Jakarta: PT Rajagrafindo Persada.

Sumar, Warni Tune dan Intan Abdul Razak. 2016. Strategi Pembelajaran Dalam Implementasi Kurikulum Berbasis Soft Skill. Yogyakarta:Deepublis.

Suprijono, Agus. 2014. Cooperative Learning Teori dan Aplikasi PAIKEM, Cet. XIV. Yokyakarta: Pustaka Pelajar.

Tarigan, Henry Guntur. 1981. Membaca Sebagai Suatu Keterampilan Berbahasa. Bandung: FKSS IKIP.

Tarigan, Henry Guntur. 1980. Menyimak Sebagai Suatu Keterampilan Berbahasa. Bandung: FKSS IKIP.

Uno, Hamzah B. 2015. Teori Motivasi \& Pengukurannya Analisis di Bidang Pendidikan. Jakarta: PT Bumi Aksara. 